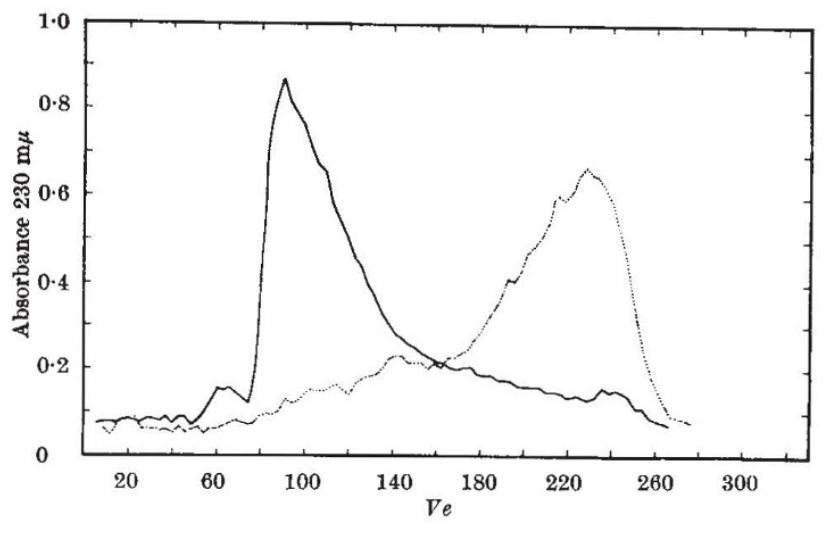

Fig. 2. Effect of snake venom on unfractionated microsomal structural protein. Frontal analysis on 'Sephadex $G-100$ ' column in 0.025 molar tris-hydrochloric acid buffer of $p \mathrm{H} 8.6$ containing 0.05 molar sodium chloride. -

100,000 is indicated by the asymmetry on the side of the trailing edge. Exposure to snake venom gives a main band corresponding to a small particle weight of about 3,000 ; intermediate particle sizes are demonstrated by the asymmetry on the side of the advancing edge. Similar evidence has been obtained from all the microsomal subfractions mentioned before. A preparation from (III) with particle weight 290,000 gave bands corresponding to 120,000 and 5,000 on treatment with snake venom. Leaving aside the question of exact values ${ }^{10}$, depolymerization of microsomal structural proteins to much smaller peptides is demonstrated.

Control experiments show that the evidence for small peptides does not come from snake venom itself. It is most likely that the phospholipase $A$ activity of the snake venom brings about depolymerization. Although albumin was not affected by the snake venom used, the possibility of the involvement of proteinases cannot be ignored.

Katalin Got

G. M. Polya

J. B. Polya

Department of Chemistry,

University of Tasmania, Hobart.

'Got, K., and Polya, J. B., Enzymology, 27, 63 (1964).

${ }^{2}$ Criddle, R. S., Bock, R. M., Green, D. E., and Tisdale, H., Biochemistry, 1, 827 (1962).

${ }^{3}$ Dallner, G., Acta Pathol. et Microbiol. Scand. Suppl., 166 (1963).

- Collins, F. D., and Shotlander, V. L., Biochem. J., 79, 321 (1961).

' Getz, C. S., and Bartley, W., Biochem. J., 78, 307 (1961).

- Gent, W. L. G., Gregson, N. A., Gammack, D. B., and Raper, J. H., Nature, $204,553(1964)$.

' Pollak, J. K., and Shorey, S. D., Biochem. J., 93, 36 C (1964).

Richardson, S. H., Hultin, H. O., and Fleischer, S., Arch. Biochem. Biophys., 105, 254 (1964).

- Andrews, P., Biochem. J., 91, 222 (1964).

${ }^{10}$ Nichol, L. W., A ustral. J. Sei., 27, 342 (1965).

\section{Occurrence of Xylose in Human Glycoproteins}

XYLOSE has not previously been identified in the prosthetic groups of human mucopolysaccharides and glycoproteins from urine and serum, although the monosaccharides galactose, mannose and fucose do occur. Our work has now shown, however, that xylose can always be found in the glycoproteins isolated from the urine of patients with inflammatory processes, tumours, plasmacytomas and, indeed, from normal persons.

The glycoproteins were hydrolysed with 'Amberlite' $C G 120$ in $0.1 \mathrm{~N}$ hydrochloric acid at $100^{\circ} \mathrm{C}$ for $4 \mathrm{~h}$. This was followed by passage through an 'Amberlite' column to remove amino-acids, amino-sugars and salts. The sugars were finally separated by the $M N$-cellulose thin-layer chromatography method of Vomhof and Tucker ${ }^{1}$. A mixture of $t$-butanol, ethyl-methyl-ketone, formic acid and water in the proportions $8: 6: 3: 3$ was used as a solvent. Xylose was identified by repeating the paper chromatography, as well as by thin-layer chromatography of plates, using $R_{F}$ values and spray reagents with various colour reactions. The xylose was further confirmed by gas chromatography using a column OS 138 polyphenylether, and a maximum temperature of $220^{\circ} \mathrm{C}$.

The thin-layer chromatogram zones developed by using anilin hydrogen phthalate were eluted and the various sugars were quantitatively determined by colorimetry using the modified method of Wilson ${ }^{2}$. As well as the xylose, which made up 2 per cent of the total glycoprotein of the urine, we also found galactose $(9 \cdot 5-10 \cdot 5$ per cent), mannose (4-4.5 per cent), fucose $(2.5$ per cent) and a small amount of glucose $(0 \cdot 2-0 \cdot 4$ per cent) as well as a lactone of glucuronic acid (a by-product of the hydrolysis). Xylose was also found in the fraction of human serum soluble in perchloric acid. In the mucopolysaccharides of gall bladder bile obtained by direct aspiration, xylose was in fact the main sugar component.

These findings are of interest because xylose has not been assumed to be present in the carbohydrates linked to proteins in humans. It is possible that natural xylose could be formed from glucose by the formation of glucuronic acid followed by fermentative decarboxylation.

This work was supported by the Deutsche Forschungsgemeinschaft, Bad Godesburg. We thank the research laboratory of the Badische Anilin und Soda-Fabriken, Ludwigshafen, for carrying out the gas chromatography.

\section{H. WEICKER}

D. GrässLin

Medizinische Univ.-Poliklinik, Heidelberg.

${ }^{1}$ Vomhof, D. W., and Tucker, T. C., J. Chromatogr., 17, 300 (1965).

${ }^{2}$ Wilson, C. M., Anal. Chem., 31, 1199 (1959).

\section{Adrenal Catecholamine Concentration after Partial Hepatectomy}

Partral hepatectomy ${ }^{1}$ and carbon tetrachloride administration ${ }^{2}$ cause similar acute changes in the morphology of the liver of rats which are much like the focal necrosis in the centrilobular and midzonal lobular areas, the centrilobular fatty infiltration and the glycogen loss, all of which are later followed by cellular regeneration. It has been suggested ${ }^{1}$ that in the case of hepatectomy or carbon tetrachloride treatment the changes result from a massive release of catecholamines which involves a drastic reduction of blood flow in the liver, an accumulation in the cells of lipids mobilized from the peripheral depots and the breakdown of the glycogen stores ${ }^{3}$.

Chemical blockage or surgical interruption of the sympathetic supply to the liver prevents the damage produced by carbon tetrachloride poisoning ${ }^{2}$ but not that produced by partial hepatectomy ${ }^{1}$. This suggests that the sympathetic nervous system does not participate in the pathogenesis of the liver which follows partial hepatectomy and that this pathogenesis has two explanationseither $(a)$ that the release of catecholamines is not increased after partial hepatectomy or $(b)$ that such increased release does occur but is unable to causo liver injury, and thus differs from the consequences of carbon tetrachloride administration.

We investigated this problem by the determination of the catecholamine behaviour in animals subjected to partial hepatectomy.

Fifty-six male Wistar rats, weighing about $200 \mathrm{~g}$ each, were used. Twenty-one were hepatectomized according to the method of Higgins and Anderson 4 and killed by decapitation, seven at a time, 3,6 and $24 \mathrm{~h}$ after surgery (groups $A-1, A-2$ and $A-3$ ); twenty-one more rats were sham-operated and killed as above (groups $B \cdot 1, B-2$ and 